\title{
Dramatic radiotherapy response in a necrotic lymphoma mass: a case report
}

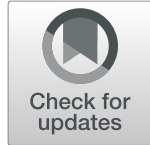

Nicholas McNeil ${ }^{1 *}$, Peter Gorayski ${ }^{1,2}$, Danielle Blunt ${ }^{1}$ and Daniel Roos ${ }^{1,3}$

\begin{abstract}
Background: Diffuse large B-cell lymphoma (DLBCL) represents the most common form of non-Hodgkin lymphoma and is characterized by an aggressive natural history. It often presents with rapid symptom development and disease progression. Most lymphomas are inherently radiosensitive, which allows for effective disease control from relatively low radiation doses. We report a case of a dramatic radiotherapy response in a necrotic diffuse large B-cell lymphoma mass in an elderly patient with early-stage diffuse large B-cell lymphoma, illustrating the potential for palliative radiotherapy to reduce disease burden in patients not fit for systemic therapy. There is no current consensus recommendation for radiotherapy treatment in this setting.

Case presentation: A 97-year-old Caucasian woman presented to the emergency department of our institution with a painful, malodorous, necrotic right upper neck mass, which had progressed over a two-month period. Investigations confirmed stage 1A diffuse large B-cell lymphoma. Palliative radiotherapy was delivered to a dose of 25 Gray (Gy) in five fractions on alternate days over two consecutive weeks. After four months, the mass completely resolved with no residual symptoms.

Conclusion: Dramatic responses resulting in durable local control and improvement in quality of life are achievable with palliative radiotherapy, owing to the radiosensitivity of diffuse large B-cell lymphoma.

Keywords: Lymphoma, Palliative, Radiotherapy, Radiosensitivity
\end{abstract}

\section{Background}

Non-Hodgkin lymphoma (NHL) includes over 50 histologic subtypes, of which diffuse large B-cell lymphoma (DLBCL) is the most common form of aggressive lymphoma, representing $30 \%$ of cases [1]. It can present with rapid symptom development and disease progression.

DLBCL presents most commonly (65\% of cases) with painless, rapidly enlarging lymphadenopathy in the cervical and abdominal regions [2]. Thirty percent of patients also present with B-symptoms, including night sweats, weight loss and fever [2]. The disease can either transform from a low-grade lymphoma or develop as de novo high-grade disease [2]. It has a slight male preponderance and median age of 64 years at diagnosis [2].

\footnotetext{
* Correspondence: nicholas.mcneil@sa.gov.au

${ }^{1}$ Royal Adelaide Hospital, Adelaide, SA, Australia

Full list of author information is available at the end of the article
}

Gene expression profiling has allowed subclassification of DLBCL by its cell of origin into either the germinal center B-cell (GCB) or activated B-cell (ABC) type. This subtyping has prognostic significance [3], with GCBDLBCL having better clinical outcomes than ABCDLBCL [4].

Radiotherapy has been used for many years to effectively treat NHL of both low- and high-grade, in the primary, consolidative, salvage and palliative settings [5]. For localized disease, systemic treatment is combined with radiotherapy [6], which in this setting results in improved progression-free survival and reduced disease recurrence at the primary site [6]. For advanced DLBCL, radiotherapy is used in the management of large volume disease to improve local disease control [6].

Patients are frequently elderly, however, limiting the ability to effectively and safely deliver systemic therapy. 
Low-dose involved-field radiation therapy of varying dose schedules has been shown to effectively palliate symptoms from advanced lymphoma [6]. Doses as low as 4 Gray (Gy) delivered over two fractions have been shown to result in $50-80 \%$ response rates for DLBCL at 21 days $[6,7]$, with a median time to disease progression following radiotherapy of 12 months [6]. Treatment with hypofractionated schedules (dose $>2$ Gy per fraction), including $8 \mathrm{~Gy}$ in a single fraction, have also been used in this setting to provide effective symptom control, with minimal toxicity and inconvenience to patients $[8,9]$. Higher-dose hypofractionated schedules with total doses of 8-30 Gy are recommended in the International Lymphoma Radiation Oncology Group (ILROG) guidelines [10]. We report a case of a dramatic radiotherapy response in a necrotic lymphoma mass in an elderly patient with early-stage DLBCL, illustrating the potential for single modality palliative radiotherapy to reduce disease burden in patients not fit for systemic therapy.

\section{Case presentation}

A 97-year-old Caucasian woman presented to the emergency department of our institution with a painful, malodorous, necrotic right submandibular mass (Fig. 1). A solitary enlarged lymph node had been identified in this region on computed tomography two months prior. She gave no history of B-symptoms, immunodeficiency or immunosuppression.

She lived at home alone with support from a carer who visited twice daily. She did not smoke tobacco or consume alcohol. Her comorbidities included dementia, congestive cardiac failure, paroxysmal atrial fibrillation, a previous above-knee deep vein thrombosis and earlystage breast cancer diagnosed 17 years earlier, managed surgically and considered to be in remission. Her regular medications included bisoprolol $2.5 \mathrm{mg}$ daily, ramipril

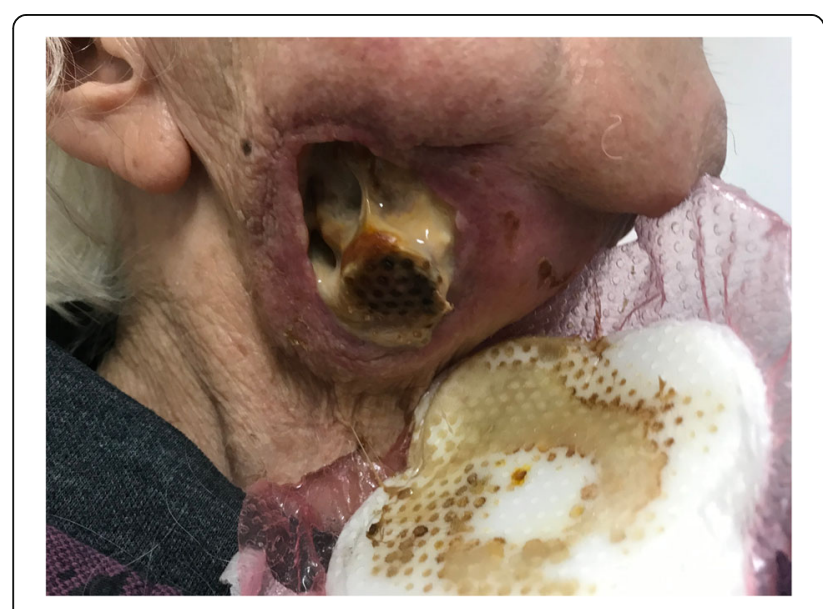

Fig. 1 The patient's right neck at presentation
$1.25 \mathrm{mg}$ daily, aspirin $100 \mathrm{mg}$ daily, digoxin $62.5 \mu \mathrm{g}$ daily and periciazine $2.5 \mathrm{mg}$ daily.

She was afebrile and hemodynamically normal at presentation and other than the right neck mass, her physical examination was unremarkable. Blood work showed a white cell count of $10.87 \times 10^{9} / \mathrm{L}$ (normal range, 4-11) with slight neutrophilia at $9.05 \times 10^{9} / \mathrm{L}$ (normal range, $1.8-7.5$ ) and lymphopenia at $1.01 \times 10^{9} / \mathrm{L}$ (normal range, 1.5-3.5). Her hemoglobin was normal at $137 \mathrm{~g} / \mathrm{L}$, as was her platelet count of $197 \times 10^{9} / \mathrm{L}$. Her potassium was measured as $3.3 \mathrm{mmol} / \mathrm{L}$ (normal range, 3.5-4.9) but all other electrolytes were within the normal range. Her creatinine measured $69 \mu \mathrm{mol} / \mathrm{L}$ with an estimated glomerular filtration rate of $64 \mathrm{ml} /$ minute $/ 1.73 \mathrm{~m}^{2}$. Her lactate dehydrogenase was elevated at $267 \mathrm{U} / \mathrm{L}$ (normal range, 110-230) but her liver enzymes were all within the normal range.

Following non-diagnostic fine needle aspiration of the mass, core biopsy revealed DLBCL with a non-germinal center immunophenotype using the Han's algorithm, and Epstein Barr encoded ribonucleic acid (RNA) in situ hybridization positivity (Figs. 2 and 3).

Computed tomography and 18-fluorodeoxyglucose (FDG) positron emission tomography (Fig. 4) revealed this to be the only site of disease, consistent with stage 1 A.

Given her age, frailty, performance status and multiple comorbidities, she was deemed unfit for systemic therapy and palliative radiotherapy was recommended.

She received a dose of $25 \mathrm{~Gy}$ delivered over five fractions on alternate days over a two-week period. Treatment was delivered using a four-beam threedimensional conformal technique with 6-megavoltage photons and daily image guidance. The treatment incorporated the use of bolus material placed over the surface of the mass to optimize the radiation dose delivered superficially to the skin.

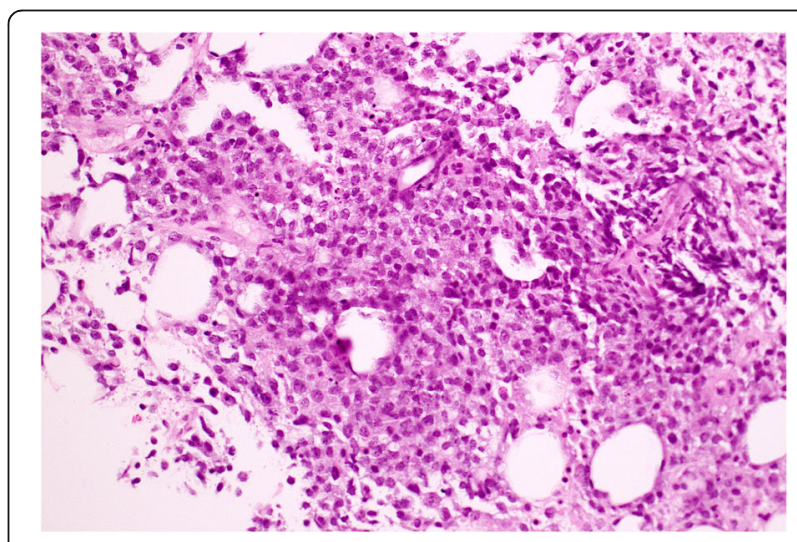

Fig. 2 Lymph node core biopsy with hematoxylin and eosin stain showing discohesive large cells with marked cellular pleomorphism and atypia 


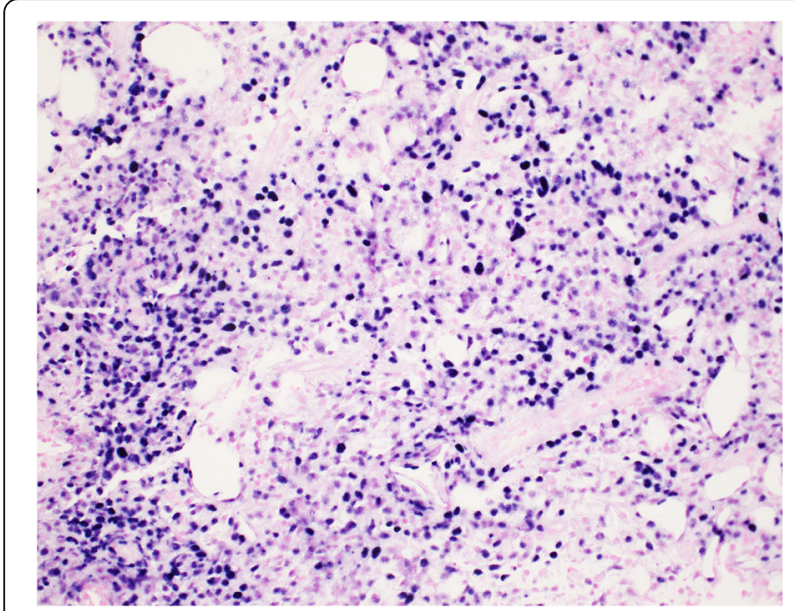

Fig. 3 Lymph node core biopsy Epstein Barr encoded RNA in situ hybridization showing a positive result

The patient was followed up monthly and after four months the mass completely resolved (Fig. 5). The overlying skin on the right neck had healed to cover the previous necrotic deficit and no mass was palpable. She was asymptomatic with no observable toxicity at the latest review at four months.

\section{Discussion}

Multimodal therapy incorporating combinations of chemotherapy, rituximab, and radiotherapy now form the basis of curative and palliative management of earlystage and advanced DLBCL [5].

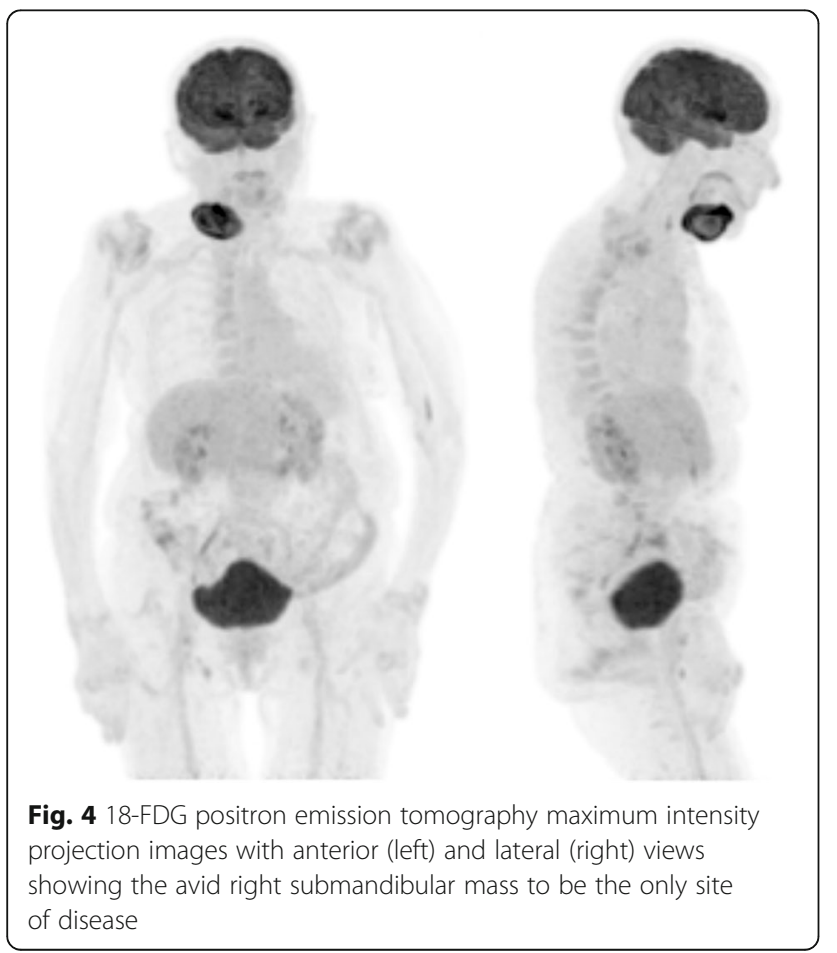

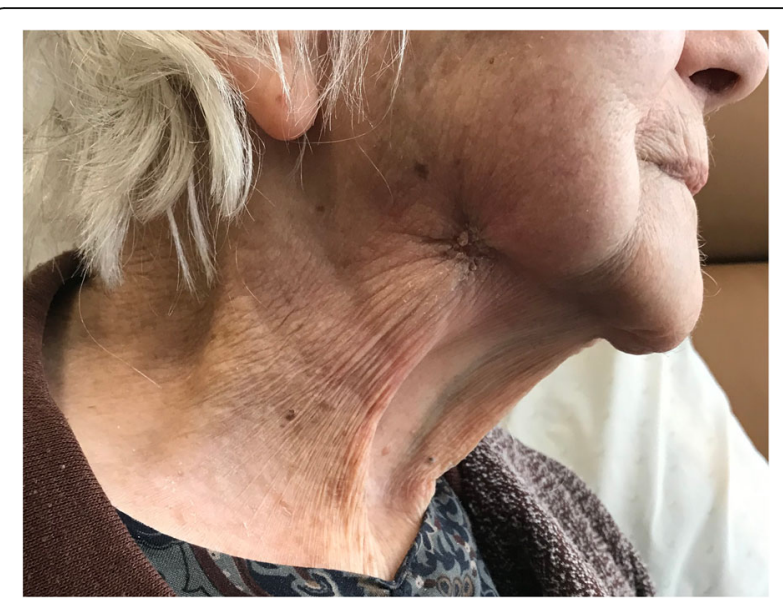

Fig. 5 The patient's right neck four months after completion of radiotherapy

In this case of an elderly woman of poor performance status, a hypofractionated course of palliative radiotherapy alone was used to treat her early-stage DLBCL. This was in part done to minimize the logistical issues relating to appointment attendance and also to allow delivery of a biological dose higher than traditional low-dose palliative treatment, with the intention of providing more robust local disease control. The dose of 25 Gy delivered over five fractions that was used represents a calculated radiobiologically equivalent dose in 2-Gy fractions (EQD2) of $31.25 \mathrm{~Gy}$, for the accepted tumor $\alpha / \beta$ ratio of $10(\alpha / \beta$ ratio represents the relative sensitivity of a tissue type to radiation).

In early-stage DLBCL (stage I-II), radiation therapy has an important role in increasing local disease control as part of combined therapy, to consolidate the effect of systemic therapy [11]. The National Comprehensive Cancer Network (NCCN) guidelines recommend total doses of 30-36 Gy following a complete response to systemic therapy and 40-50 Gy following a partial response [12].

For patients with DLBCL who are unsuitable for systemic therapy, single-modality radiotherapy used as primary treatment has been shown to provide effective local control [11]. Specifically in the setting of relapsed or refractory disease in patients unfit for systemic treatment, the ILROG guidelines recommend radiotherapy with curative intent to locoregionally confined disease to a total dose of 45-55 Gy, delivered in doses of 1.8-2 Gy per fraction [10].

In the palliative setting, the role of radiotherapy is well established for the multimodal treatment of refractory or relapsed DLBCL, or as single-modality treatment for those unfit for systemic therapy. Low-dose radiotherapy, accepted as doses $\leq 8$ Gy delivered in one or more fractions, has been shown in a number of trials to be 
effective in providing local disease control [6-8]. Brady et al., in their 2016 trial, compared the palliative radiotherapy schedules of $8 \mathrm{~Gy}$ delivered in a single fraction with 4. Gy in one or two fractions and showed no significant difference in overall response rates [8]. For this purpose, the ILROG guidelines support the use of hypofractionated schedules of 8-30 Gy, depending on the adjacent dose-limiting normal structures [10].

Wong et al., in their 2018 population-based retrospective review of the efficacy of palliative radiation therapy for DLBCL, showed it to be effective for both managing symptoms and providing local disease control [13]. They reviewed 217 patients with a mean age 76 years who received a total of 370 courses of palliative radiotherapy for DLBCL. The median dose delivered had an EQD2 of $19 \mathrm{~Gy}$, considerably lower than the EQD2 of $31.25 \mathrm{~Gy}$ in the treatment of our patient. Symptom resolution was reported in $42 \%$ of patients overall and following each individual treatment course, $51 \%$ of patients reported pain resolution and 36\% reported pain improvement. Local control six months after treatment was achieved in $65 \%$ of patients. The authors did not identify a significant association between the EQD2 dose of the delivered treatment and the rate of local control achieved.

There is no consensus recommendation for a specific dose-fractionation schedule in the setting of single modality primary radiotherapy for early-stage DLBCL. In this case, patient, tumour and treatment factors, tumor and treatment factors were all considered in determining the high palliative dose of $25 \mathrm{~Gy}$ in five fractions, which proved highly effective in providing local disease control.

\section{Conclusion}

We report a remarkable response to radiotherapy in an elderly patient with early-stage DLBCL, illustrating the potential for palliative radiotherapy to reduce disease burden in patients otherwise not fit for systemic therapy. Importantly, lymphomas are among the most radiosensitive cancers, with the radiotherapy dose tailored to the performance status of the individual, which results in minimal toxicity in the majority of cases.

\section{Abbreviations}

ABC: Activated B cell; DLBCL: Diffuse large B-cell lymphoma;

EQD2: Equivalent dose in 2 Gy per fraction; FDG: Fluorodeoxyglucose; GCB: Germinal center B-cell; Gy: Gray; ILROG: International Lymphoma Radiation Oncology Group; NCCN: The National Comprehensive Cancer Network; NHL: Non-Hodgkin lymphoma; RNA: Ribonucleic acid

\section{Acknowledgements}

Not applicable.

\section{Authors' contributions}

All authors contributed equally to the preparation of this case report. All authors read and approved the final manuscript.

\section{Authors' information}

Department of Radiation Oncology, Royal Adelaide Hospital, Adelaide, South Australia, Australia

Dr. Nicholas McNeil, MBBS, DipPallCare, MPH

Radiation Oncology Registrar

Associate Professor Peter Gorayski, BSc (Hons), BMBS, FRACGP, FRANZCR

Radiation Oncology Staff Specialist^

Professor Daniel Roos, BSc (Hons), DipEd, MBBS, MD, FRANZCR

Senior Radiation Oncology Staff Specialist*

Department of Hematology, Royal Adelaide Hospital, Adelaide, South Australia, Australia

Dr. Danielle Blunt, BSC, BMBS, FRACP, FRCPA

Hematology Staff Specialist

$\wedge$ And University of South Australia, Adelaide, South Australia, Australia

*And School of Medicine, University of Adelaide, Adelaide, South Australia, Australia

Funding

Not applicable.

Availability of data and materials

Not applicable.

Ethics approval and consent to participate

Not applicable.

\section{Consent for publication}

Written informed consent was obtained from the patient for publication of this case report and any accompanying images, and this written consent was countersigned by her medical agent. A copy of the written consent is available for review by the Editor-in-Chief of this journal.

\section{Competing interests}

The authors have no financial or nonfinancial competing interests to declare.

\section{Author details}

${ }^{1}$ Royal Adelaide Hospital, Adelaide, SA, Australia. ${ }^{2}$ University of South Australia, Adelaide, SA, Australia. ${ }^{3}$ School of Medicine, University of Adelaide, Adelaide, SA, Australia.

Received: 20 November 2019 Accepted: 16 June 2020

Published online: 28 July 2020

References

1. International Lymphoma Study Group. Non-Hodgkin's Lymphoma Classification Project. A clinical evaluation of the International Lymphoma Study Group classification of non-Hodgkin's lymphoma. Blood. 1997;89: 3909-18.

2. Freedman AS, Aster JC. Epidemiology, clinical manifestations, pathologic features, and diagnosis of diffuse large B cell lymphoma. In: UpToDate. Lister, A (Ed). UpToDate. Waltham, MA, USA. 2012.

3. Hans CP, Weisenburger DD, Greiner TC, Gascoyne RD, Delabie J, Ott G, Müller-Hermelink HK, Campo E, Braziel RM, Jaffe ES, Pan Z. Confirmation of the molecular classification of diffuse large B-cell lymphoma by immunohistochemistry using a tissue microarray. Blood. 2004;103:275-82.

4. Tilly H, Gomes da Silva M, Vitolo U, et al. Diffuse large B-cell lymphoma (DLBCL): ESMO clinical practice guidelines for diagnosis, treatment and follow-up. Ann Oncol. 2015;26(Suppl 5):v116-25.

5. Zimmermann M, Oehler C, Mey U, Ghadjar P, Zwahlen DR. Radiotherapy for non-Hodgkin's lymphoma: still standard practice and not an outdated treatment option. Radiat Oncol. 2016;11:110.

6. Murthy V, Thomas K, Foo K, Cunningham D, Johnson B, Norman A, Horwich A. Efficacy of palliative low-dose involved-field radiation therapy in advanced lymphoma: a phase II study. Clin Lymphoma Myeloma. 2008;8: 241-5.

7. Furlan C, Canzonieri V, Spina M, Michieli M, Ermacora A, Maestro R, Piccinin S, Bomben R, Dal Bo M, Trovo M, Gattei V. Low-dose radiotherapy in diffuse large B-cell lymphoma. Hematol Oncol. 2017;35:472-9.

8. Tanaka O, Oguchi M, lida T, Kasahara S, Goto H, Takahashi T. Low dose palliative radiotherapy for refractory aggressive lymphoma. Rep Pract Oncol Radiother. 2016;21:495-9. 
9. Brady JL, Attallah H, Mikhaeel NG. Outcome of low-dose palliative radiation therapy in relapsed or refractory high-grade non-Hodgkin lymphoma [abstract]. Int J Radiat Oncol Biol Phys. 2016;96(2 Suppl):E493.

10. Ng AK, Yahalom J, Goda JS, Constine LS, Pinnix CC, Kelsey CR, Hoppe B, Oguchi M, Suh CO, Wirth A, Qi S. Role of radiation therapy in patients with relapsed/refractory diffuse large B-cell lymphoma: guidelines from the International Lymphoma Radiation Oncology Group. Int J Radiat Oncol Biol Phys. 2018;100(3):652-69.

11. Illidge T, Specht L, Yahalom J, Aleman B, Berthelsen AK, Constine L, Dabaja B, Dharmarajan $\mathrm{K}, \mathrm{Ng} \mathrm{A}$, Ricardi U, Wirth A. Modern radiation therapy for nodal non-Hodgkin lymphoma - target definition and dose guidelines from the International Lymphoma Radiation Oncology Group. Int J Radiat Oncol Biol Phys. 2014;89(1):49-58

12. National Comprehensive Cancer Network (NCCN). NCCN Clinical Practice Guidelines in Oncology (NCCN Guidelines) Non-Hodgkin's Lymphoma. Version 3. 2019. http://www.nccn.org. Accessed 20 Dec 2019.

13. Wong J, Pickles T, Connors JM, Aquino-Parsons C, Sehn L, Freeman C, Lo AC. Efficacy of palliative radiation therapy (RT) for diffuse large B-cel lymphoma: a population-based retrospective review [abstract]. Int J Radiat Oncol Biol Phys. 2018;102(3 Suppl):E365.

\section{Publisher's Note}

Springer Nature remains neutral with regard to jurisdictional claims in published maps and institutional affiliations.

Ready to submit your research? Choose BMC and benefit from:

- fast, convenient online submission

- thorough peer review by experienced researchers in your field

- rapid publication on acceptance

- support for research data, including large and complex data types

- gold Open Access which fosters wider collaboration and increased citations

- maximum visibility for your research: over $100 \mathrm{M}$ website views per year

At BMC, research is always in progress.

Learn more biomedcentral.com/submissions 